\title{
Homo eller hetero - spiller det noen rolle hva pasienten er?
}

\author{
Ved Morten S. Selle
}

\begin{abstract}
De senere år har det blitt økt oppmerksomhet omkring at en del homofile og lesbiske har psykiske problemer og en økt forekomst av selvmordsproblematikk. Dette synes uventet i vårt tolerante samfunn med partnerskapslovgivningen fra 1993, med kjente politikere som er åpne homofile osv. Tross denne positive utviklingen i samfunnets holdninger er det likevel en gruppe homofile og lesbiske som på forskjellig vis sliter, også i møtet med helsevesenet. Det er viktig å ha kunnskap om mulige sammenhenger og forklaringsmodeller, og om helsepersonells egne holdninger, slik at man kan møte disse pasientene på en best mulig måte i helsevesenet.
\end{abstract}

\section{Homofili er ikke patologi}

M edisinens og psykologiens forhold til homoseksualitet og homofile og lesbiske har gjennomgått store forandringer i løpet av noen få generasjoner. På slutten av 1800-tallet begynte medisinen å interessere seg for homoseksual itet som en patologisk tilstand, dels etter initiativ fra homofile selv. Dette var etter hvert med på å humanisere strafferetten ettersom homofili ble oppfattet som sykdom, selv om homoseksuelle handlinger var straffbare helt til 1972 i N orge. O fte ble forskjellige behandlinger forsøkt i stedet for straff (Selle, 2001).

Fra 1950-tallet begynte det å komme undersøkelser og rapporter som tydet på at homofili ikke var forbundet med psykopatologi (H ooker, 1957). Etter mye debatt avskaffet den amerikanske psykiaterforeningen diagnosen i 1974. I N orge anbefalte N orsk psykiatrisk forening i 1977 at homoseksual itet ikke skulle brukes som diagnose i N orge. Først i 1992 ble diagnosen fjernet fra det internasjonale diagnosesystemet ICD-10 av Verdens helseorganisasjon.

\section{Homofili og økt risiko for suicidalitet}

I debattene som førte til at homoseksualitet ble avdiagn ostisert, var det viktig å vise at homoseksualitet ikke var forbundet med psykopatologi. På 1990-tallet ble man mer oppmerksom på at noen homofile kvinner og menn hadde økte psykiske vansker, blant annet i form av selvmordstanker og -forsøk. Etter hvert kom undersøkel ser som rapporterte om økt forekomst av psykiske vansker hos homofile kvinner og menn. I N orge ble disse funnene bekreftet i den store levekårsundersøkelsen blant homofile menn og lesbiske som kom i 1999. Resultatene viste at risikoen for sel vmordstanker var seks til syv ganger høyere enn i den øvrige befolkningen. $M$ est alarmerende var funnene om at hver fjerde homofile mann under 25 år hadde minst ett selvmordsforsøk bak seg. U ndersøkel sen viste at unge homoseksuelle (1624 år) hadde opptil fire ganger så høy forekomst av selvmordsforsøk som heteroseksuelle i samme aldersgruppe ( $H$ egna et al, 1999). Dette stemmer med andre internasjonale studier. U ndersøkelser fra $\mathrm{N}$ ew Zealand og U SA tyder på at homoseksuell ungdom har økt forekomst av psykiske problemer, særlig depresjon, rusmisbruk og angstlidelser (Ferguson et al, 1999; Cochran \& M ays, 2000).

Tendensen i studiene er at homofile menn rapporterer fire ganger så ofte alvorlige selvmordsforsøk som heterofile menn (M cA ndrew \& Warne, 2004).

Eldre homofile og lesbiske har lett for å bli usynlige i denne sammenhengen. I en amerikansk undersøkelse blant homofile og lesbiske i alderen 60 til 91 år var det en økt forekomst av suicidalitet blant dem som hadde høy grad av internalisert homofobi, var ensomme og hadde fortalt få eller ingen om sin seksualitet ( $D$ 'A ugelli et al, 2001).

\section{Homofili og minoritetsstress}

Etter hvert er det kommet representative, generelle befolkningsundersøkelser som gjør det lettere å sammenligne svarene mellom homofile, lesbiske og heterofile. En stor nederlandsk befolkningsundersøkelse fant at blant respondentene som oppgav en homofil orientering, var det flere som rapporterte om psykiske og fysiske symptomer enn blant heterofile (Sandfort et al, 2006).

De senere års studier av sammenhengen mellom seksuell orientering og psykisk helse er blitt bedre, og tyder på at det foreligger økt risiko for stress-sensitive lidelser som kan tilskrives skadelige effekter av antihomoseksuelle holdninger (Cochran, 2001).

U ndersøkel ser blant homofile og lesbiske, og fra representative generelle befolkningsundersøkel ser, viser at homofil orientering kan være en risikofaktor for suicidalitet, spiseforstyrrelser, rusproblemer, depresjon og angstlidel ser ( $M$ eyer, 2003; Sandfort, 2006). Data tyder på at dette særlig gjelder unge, det vil si under 40 år (W arner et al, 2004). Seksuell orientering kan være en risikofaktor for psykiske problemer slik som andre individuelle risikofaktorer som kjønn, alder og etnisk bakgrunn (C ochran et al, 2003). Det er påfallende at tallene for selvmordsforsøk og -handlinger stort sett er uendret helt fra de første undersøkelsene av suicidalitet hos homofile menn fra 60-tallet og frem til i dag (Herrell et al, 1999). Dette til tross for samfunnsmessige holdningsendringer som har skjedd med avkriminalisering, avdiagnostisering og partnerskapslovgivning. Fremti dige undersøkelser vil vise om denne tendensen endrer seg etter hvert som samfunnets holdninger og kunnskaper gjør seg gjeldende også på individnivå.

R apporter om økt alkoholforbruk, selvmordsadferd og mer angst og depresjon hos homofile, er tilsynelaten de uforenlig med det moderne synet på homofili som en ikke-patologisk normalvariant. Imidlertid er det slik at ingen studier har påvist distinkte forskjeller i personlighetsutformingen blant homofile sammenlignet med heterofile (H ooker, 1957; Friedman \& Downey, 1994). Det er heller ikke påvist psykopatologi som bare finnes hos homofile eller bare hos heterofile (G onsiorek \& W einrich, 1991: 115-37). Funnene som tyder på at homofili kan være en risikofaktor for psykiske problemer, kan best forklares med omgivelsenes stigmatiserende holdninger til homofili. En mer omfatten de modell er å se dette som minoritetsstress (Sandfort et al, 2006), en forklaring som innebærer opplevd stress fra ytre hendelser og betingelser, forventningene om dette, den årvåkenheten dette innebærer, internaliseringen av negative holdninger og oppfattel ser (internalisert homofobi), og at man skjuler sin seksuelle orientering ( $M$ eyer, 
2003). Internalisert homofobi peker seg ut i flere undersøkelser som viktig for forekomsten av angst, depresjon, rusmisbruk og suicidalitet (M eyer, 2003).

\section{Kontakt med helsevesenet}

Erfaring tyder på at noen homofile og lesbiske opplever fordommer og negative holdninger i møtet med helsevesenet, noe som kan medføre dårligere kvalitet av behandling og pleie. I en svensk undersøkel se blant 165 sykepleiere, hjelpepleiere og studenter, rapporterte de fleste positive holdninger. M en $30 \%$ var nøytrale, det vil si at de uttrykte verken positive eller negative holdninger til homofile og lesbiske (Röndahl et al, 2004) . 0 gså i helsevesenet dominerer en heteronormativitet som medfører at vi tar det for gitt at alle våre pasienter er heterofile. Det kan bidra til å usynliggjøre homofili. Dette kommuniseres direkte og indirekte til homofile og lesbiske pasienter. En homofil eller lesbisk pasient kan frykte å bli møtt med fordommer eller avvisning, og kan derfor synes det er vanskelig å fortelle om seksual itet, kjæreste osv, som kan være vesentlige faktorer for pasientens aktuelle situasjon.

I en svensk undersøkelse ble homofile og lesbiske pasienter og pårørende spurt om sine erfaringer i forbindelse med sykehusopphold. Svarene de ga, viste hvordan enkelte av pleiepersonalet ble perplekse over pasientens seksuelle legning, og at kommunikasjonen kunne lide under at enkelte av personalet var redde for å opptre ukorrekt. R espondentene råder hel sepersonell til å bruke kjønnsnøytrale begreper som kjæreste, partner, ektefelle; huske at ikke alle pasienter er heterofile og at homofile og lesbiske ikke skal behandles som totalt forskjellige fra heterofile (Röndahl et al, 2006).

Både amerikanske og britiske undersøkelser viser at homofile og lesbiske har oftere kontakt med det psykiske helsevern enn heterofile (C ochran et al, 2003; King et al, 2003).

U ndersøkel ser fra utlandet bekrefter at homofobi finnes blant leger og annet helsepersonell (Rose, 1994; C haimowitz, 1991).

I kontakten med det psykiske hel severn vil det erfaringsmessig være noen som ikke føler seg trygge nok til å fortelle om sin seksual itet i frykt for fordommer og diskriminering. En undersøkelse fra Stor- britannia viser at mange homofili har hatt negative møter med helsevesenet på bakgrunn av sin seksuelle orientering. $\mathrm{H}$ alvparten av de spurte mente å ha erfart at deres seksualitet ble brukt som forklaring på deres psykiske problemer (M cFarlane, 1998).

\section{Internalisert homofobi}

Både pasienter og helsepersonell er vokst opp i et samfunn som både har devaluert og fryktet homoseksual itet og definert det som sykdom, som avvikende og umoralsk adferd (Kjær, 2001). De vanligste stereotypier om homofile dreier seg om promiskuitet, forføringsteorien (at man kan forføres til å bli homofil), sammenblanding av begreper (pedofile er homofile), at feminine homofile menn egentlig ønsker å være kvinner, at homofile kvinner hater menn, at alle homofile parforhold er kortvarige, at det alltid er en "kvinne" og en "mann" i et homofilt parforhold osv.

Vedvarende eksponering for antihomoseksuelle holdninger og adferd vil kunne føre til internalisering av negative selvoppfatninger hos en homofil eller lesbisk person. På samme måte kan også heterofile ha mer eller mindre ubevisste negative fordommer om homofili. Dessuten påvirkes vi av samfunnets heteronormativitet, som innebærer ideal isering av heteroseksualiteten og en uuttalt oppfatning av heteroseksualitet som det selvsagte og det naturlige. I lærebøker kan en se dette ved at homoseksualitet ofte er et eget stikkord eller overskrift, mens heteroseksual itet omtales under den generelle overskriften "seksualitet". I et slikt perspektiv er det mer hensiktsmessig å tenke at homofil ungdom ikke bare er forvirret over sin seksualitet, men snarere at de er forvirret og frustrert over hvordan de skal kunne uttrykke homoseksualiteten i et fiendtlig sosialt miljø (H errell et al, 1999).

\section{Eksempler på \\ indirekte stigmatisering}

Internalisert homofobi eller antihomoseksuelle holdninger kommer til uttrykk på mange måter. U tsagn som: "Du er så ung, dette er bare en fase som går over; du som er så maskulin/feminin kan da ikke være ... ; hvis du ikke er helt sikker på om du liker mest gutter eller jenter, betyr nok det at du egentlig er heterofil", formidler at homofili er en uønsket og mindreverdig tilstand. Vi kan anta at heteroseksuelle erfaringer betyr at pasienten er heteroseksuell, mens homoseksuelle erfaringer blir beskrevet som "eksperimentering". Det kan gjenspeile seg i at vi blir mest interessert i å høre om de heteroseksuelle erfaringene og viser minimal interesse for eventuelle homoseksuelle erfaringer. Det kan antas at pasientens uvilje mot å omtal e seg selv som homofil, må bety at pasienten er heterofil. U ten videre aksepteres forklaringsutsagn fra pasienten av typen "da jeg var 12 var det en voksen mann som ... så det er vel derfor at jeg... " eller "far var lite hjemme, det er vel derfor jeg kanskje er homoseksuell". Pasi enten kan komme med påstander om at homoseksualitet er ensbetydende med aids, og at alle homofile er ulykkelige selvmordskandidater, uten å bli møtt med innsigelser. På spørsmål om hva vi mener og synes om homoseksualitet, kan pasienten få unnvikende svar som: "Jeg kjenner mange som er homofile." Konsekvent bruk av det påpekende pronomenet "de" er med på å signalisere avstand og annerledeshet ("De homofile" i stedet for "H omofile"). Dette er alle eksempler på antihomoseksuelle holdninger eller homofobi både hos helse-personell og pasient, og gir signaler om homoseksualitet som ubehagelig og uønsket. H elsepersonell må altså forholde seg til både ekstern homofobi, det vil si effektene av samfunnets holdninger, og til internalisert homofobi, både hos seg selv og hos pasienten.

U ndersøkelser viser at en positiv oppfatning av egen homoseksualitet er forbundet med bedre sel vfølelse og mindre angst (D upras, 1994). Dette stemmer godt med den norske undersøkelsen som viste økt antall selvmordsforsøk hos unge i alderen 16-24 år og hvor begrunnelsen var knyttet til et dårlig selvbilde ( $\mathrm{H}$ egna et al, 1999). U ndersøkelser tyder på at de som ikke åpent aksepterer sin homoseksualitet, har tendens til å score høyere på depresjon og mistilpasning i relasjoner (M cFarlane, 1998). Følel sene av skam og skyld er ofte sterke, både i forhold til de seksuelle følelsene, men også i forhold til det å leve "skjult". D et å leve skjult innebærer at en ikke kan være autentisk i forhold til andre fordi en seiler under falsk flagg som heterofil og må anstrenge seg for ikke å bli avslørt. 
$M$ ed andre ord kan det konkluderes med at det er bra for helsen å komme ut av skapet (Dupras, 1994).

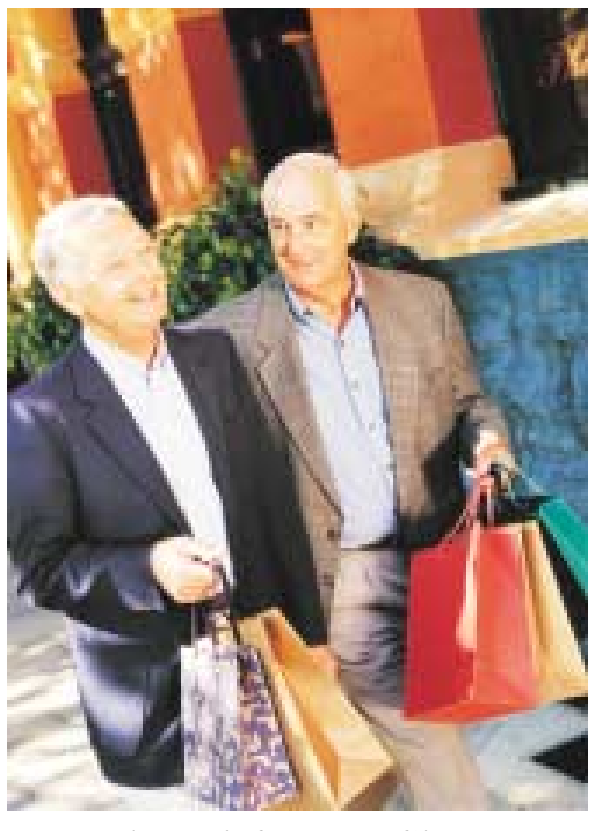

$\AA$ identifisere seg som homofil eller lesbisk innebærer også en taps- og sorgprosess i det man sier farvel til den sosialt forventede og aksepterte heterofile identitet, og dermed også tap av planer og "ønsker" om ekteskap, barn og barnebarn som en selv og omgivelsene tok for gitt som en del av livsplanene, i tillegg til risikoen for å bli avvist av sin familie. For den som skal hjelpe en person med å kartl egge sin seksuelle orientering, er det viktig å huske at dette dreier seg om flere dimensjoner på en gang: drifter, begjær, lengsl er, fantasier, seksuell adferd, emosjonell tiltrekning og selvidentifisering (det vil si om man identifiserer seg som heteroseksuell, homoseksuell, biseksuell, lesbisk eller homse). Disse dimensjonene er ikke nødven digvis konstante i tid og innebærer mulighet for variasjon og mangfold. I tillegg kommer begreper og kategorier som kjønnsroller, kjønnsidentitet og livsstil. Det er derfor viktig å utforske og kartlegge hva slags tanker, forestillinger og fordommer pasienten har om homoseksual itet. 0 fte vil en som er i tvil om og i konflikt med sin seksual itet, omtal e homoseksuelle på en negativ måte. $M$ ange menn strever med frykt for selve seksuallivet som assosieres med smitte og sykdom ( særlig H IV og A IDS).
H omofile og lesbiske pasienter trenger ikke annen tilnærming enn heterofile pasienter. D et som er viktig er å ha kjennskap til visse forhold som i perioder kan være av betydning for homofile og lesbiske. Disse forholdene kan oppsummeres i følgende stikkord:

1. A nnerledeshet

2. Avvisning

3. Isolasjon

4. M angelfull speiling og bekreftelse

5. Skam

6. Internalisert homofobi

7. Tapsopplevelser

\section{Konklusjon}

I tillegg til kunnskap om selvmord generelt, er det viktig at hel sepersonell også har kunnskap om viktige livserfaringer som homofile og lesbiske gjør i forbindelse med sin seksuelle identitet. Dessuten er det en fordel å være klar hvordan vi bevisst og ubevisst formidler våre egne holdninger og oppfatninger.

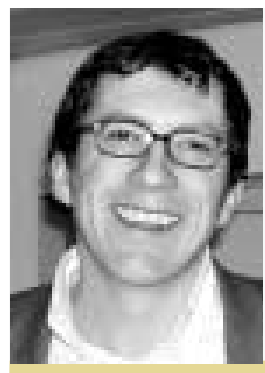

M orten S. Selle er psykiater og overlege ved Psykiatrisk avdeling,Vinderen, Diakonhjemmet sykehus. $\mathrm{H}$ an har vært bidragsyter i antologien $\mathrm{N}$ orsk H omoforskning, U niversitetsforlaget 2001 og til Einar Kringlen: Psykiatri, Gyldendal 2001.

\section{Referanser:}

Chaimowitz, G .A . (1991): H omophobia among psychiatric residents, family practice residents and psychiatric faculty. C anadian Journal of Psychiatry 36, 206-209.

Cochran, S.D. \& M ays, V.M . (2000). Lifetime prevalence of suicide symptoms and affective disorders among men reporting same-sex sexual partners:

R esults from N H A N ES III. A merican Journal of Public Health 90, 4, 573-578.

Cochran, S.D. (2001). E merging issues in research on lesbians' and gay men's mental health: does sexual orientation really matter? A m Psychol 56(11) 931-47.

Cochran, S.D., M ays V.M ., Sullivan J.G . (2003). Prevalence of mental disorders, psychological distress, and mental health services use among lesbian, gay, and bisexual youth in the $U$ nited States. J Consult Clin Psychol 71(1), 53-61.

D'A ugelli, A .R., G rossman A .H ., H ershberger S.L., 0 'C onnell T.S. (2001). A spects of mental health among older lesbian, gay, and bisexual adults. A ging $M$ ental $H$ ealth 5(2), 149-58.
Dupras, A . (1994). Internalized homophobia and psychosocial adjustment among gay men.

Psychological Reports 75, 23-28.

Fergusson, D.M., H orwood, L.J., Beautrais, A .L. (1999). Is sexual orientation related to mental health problems and suicidality in young people? A rchives of $G$ eneral Psychiatry 56, 876-880.

Friedman, R.C.\& Downey, J.I. (1994). H omosexuality. The $N$ ew England Journal of M edicine $331(14), 923-930$

Gonsiorek, J.C. \& W einrich, J.D. (Red) (1991). H omosexuality R esearch implications for public policy. N ewbury Park: SA GE Publications.

H egna, K., Kristiansen, H.W., M oseng, B.U . (1999). Levevilkăr og livskvalitet blant lesbiske kvinner og homofile menn. N OVA Rapport 1/99.

H errell, R., Goldberg, ., True, W.R., Ramakrishnan, V., Lyons, M., Eisen, S. et al (1999). Sexual orientation and suicidality. A rchives of $G$ eneral Psychiatry 56 , 867-874.

H ooker, E. (1957). T he adjustment of the male overt homosexual. Journal of Projective Techniques 21, 18-31.

King, M . et al (2003). Mental health and quality of life of gay men and lesbians in England and Wales: controlled, cross-sectional study. Br J Psychiatry 183 $552-8$

Kjær, R. (2001). Seksualpsykopaten som forsvant. H omofili i norske psykiatriske lærebøker. I: Brantsæter M .C ., Eikvam T., Kjær R., Å må K.O . (red)

N orsk homoforskning. 0 slo: U niversitetsforlaget.

M cA ndrew, S., W arne T. (2004). I gnoring the evidence dictating the practice: sexual orientation, suicidality and the dichotomy of the mental health nurse. J Psychiatr M ent Health N urs 11(4), 428-34.

M CFarlane, L. (1998): Diagnosis: H omophobic. The experiences of lesbians, gay men and bisexuals in mental health services. London: PA CE.

M eyer, I.H . (2003). Prejudice, social stress, and mental health in lesbian, gay, and bisexual populations: conceptual issues and research evidence. Psychol Bull 129(5), 674-97.

Rondahl, G., Innala S., C arlsson M. (2004). N urses' attitudes towards lesbians and gay men. J A dv N urs 47(4), 386-92.

Rondahl, G ., Innala S., C arlsson M . (2006). H eterosexual assumptions in verbal and non-verbal communication in nursing. J A dv N urs 56(4), 373-81.

Rose, L. (1994). H omophobia among doctors. BM J 308, 586-7.

Sandfort, T.G ., Bakker F., Schellevis F.G ., Vanwesenbeeck I. (2006). Sexual orientation and mental and physical health status: findings from a $D$ utch population survey. A m J Public Health 96(6), 1119-25.

Selle, M.S. (2001). N ei til "behandling" - ja til terapi. En mentalhygienisk veiledning for helsepersonell og pasienter om homosek sualitet. I Brantsæter M.C, Eikvam T., Kjær R., A mås K.O. (red). N orsk homoforskning. 0 slo: U niversitetsforlaget.

Warner, J. et al (2004). R ates and predictors of mental illness in gay men, lesbians and bisexual men and women: R esults from a survey based in England and W ales. Br J Psychiatry 185, 479-85. 